\title{
Potentiation of resveratrol-induced apoptosis by matrine in human hepatoma HepG2 cells
}

\author{
XIUYUAN OU ${ }^{1,2}$, YAN CHEN $^{2,3}$, XINXIN CHENG $^{4}$, XUMENG ZHANG $^{1}$ and QIYANG HE $^{1}$ \\ ${ }^{1}$ Institute of Medicinal Biotechnology, Chinese Academy of Medical Sciences and Peking Union Medical College, \\ Beijing 100050; ${ }^{2}$ Academy of the State Administration of Grain, Beijing 100037; ${ }^{3}$ Institute of Agro-food Science \\ and Technology, Chinese Academy of Agricultural Sciences, Beijing 100193; ${ }^{4}$ Cancer Institute and Hospital, \\ Chinese Academy of Medical Sciences and Peking Union Medical College, Beijing 100021, P.R. China
}

Received June 5, 2014; Accepted August 7, 2014

DOI: $10.3892 /$ or.2014.3512

\begin{abstract}
Resveratrol, a natural polyphenolic phytochemical, has received considerable attention due to its potential chemopreventive and chemotherapeutic properties. In the present study, we first evaluated the growth-inhibitory effect of resveratrol on HepG2 cells and explored the underlying molecular mechanisms. Resveratrol inhibited proliferation and induced apoptosis in HepG2 cells via activation of caspase- 9 and caspase-3, upregulation of the $\mathrm{Bax} / \mathrm{Bcl}-2$ ratio and induction of p53 expression. Cell cycle analysis demonstrated that resveratrol arrested cell cycle progression in the $\mathrm{G}_{1}$ and $\mathrm{S}$ phase. We further focused on the combination of matrine, a natural component extracted from the traditional Chinese medical herb Sophora flavescens Ait., as a mechanism to potentiate the growth-inhibitory effect of resveratrol on HepG 2 cells. Both MTT and colony formation assay results indicated that the combined treatment of resveratrol and matrine exhibited a synergistic antiproliferative effect. In addition, resveratrol-induced apoptosis was significantly enhanced by matrine, which could be attributed to activation of caspase-3 and caspase-9, downregulation of survivin, induction of reactive oxygen species (ROS) generation and disruption of mitochondria membrane potential $\left(\Delta \psi_{\mathrm{m}}\right)$. Our findings suggest that the combination treatment of resveratrol and matrine is a promising novel anticancer strategy for liver cancer; it also provides new insights into the mechanisms of combined therapy.
\end{abstract}

\section{Introduction}

Liver cancer is the fifth most common cancer in men and the seventh in women; it accounts for $9 \%$ of all cancer-related deaths worldwide and $12 \%$ in developing countries (1).

Correspondence to: $\mathrm{Dr}$ Yan Chen, Academy of the State Administration of Grain, No. 11 Baiwanzhuang Street, Beijing 100037, P.R. China

E-mail: chenyan8855@163.com

Key words: hepatocellular carcinoma, resveratrol, matrine, apoptosis
Epidemiologic studies have shown that the main risk factors for hepatocellular carcinoma (HCC) are chronic hepatitis B virus (HBV) and hepatitis $\mathrm{C}$ virus $(\mathrm{HCV})$ infections $(2,3)$. Among primary live cancers, HCC accounts for almost $70-85 \%$ of the total liver cancer burden. Until recently, there is still a lack of systemic chemotherapy in treating HCC efficaciously. Although sorafenib has been approved by FDA for the treatment of advanced HCC, it causes several adverse effects including diarrhea, hand-foot skin reaction, hypophosphatemia and the risk of bleeding $(4,5)$. Therefore, it is urgent to develop alternative therapeutic strategies for liver cancer.

Resveratrol, a naturally occurring polyphenolic compound, is commonly present in the skin of grapes and in red wine (6). Due to its high toxicity toward tumor cells, resveratrol appears to be a good candidate drug for cancer therapy. Resveratrol can delay or prevent all stages of carcinogenesis in vitro and in vivo, including initiation, promotion and progression $(6,7)$. When resveratrol is combined with other anticancer agents, such as 5-fluorouracil and curcumin, they display synergistic anticancer properties (8-10). Previous studies have also demonstrated that resveratrol inhibits cell proliferation and induces apoptotic cell death in HCC cells in vivo and in vitro (7).

Matrine is an important ingredient of a traditional Chinese herb Sophora flavescens Ait., which has widely been used in China for the treatment of viral hepatitis, liver cirrhosis, cardiac arrhythmia and skin inflammations without any obvious side-effects (11). Recently, its anticancer activity has been extensively investigated; it inhibits proliferation and metastasis and induces apoptosis in a variety of malignant cells (12-15). It also reduces the occurrence of multidrug-resistant tumor cells induced by chemotherapy and displays synergistic activities with other anticancer agents $(16,17)$. Matrine inhibits the growth of HCC cells by inducing apoptosis via upregulation of the ratio of $\mathrm{Bax} / \mathrm{Bcl}-2$ (13). However, matrine alone weakly inhibits proliferation of cancer cell lines with an $\mathrm{IC}_{50}$ value of 2-16 mM (17).

In the present study, we first evaluated the antiproliferative effect of resveratrol on HepG2 cells and then explored the underlying molecular mechanisms. Since both resveratrol and matrine independently exert anticancer activities against liver cancer cells, it led us to hypothesize that an increased benefit would result when using the combination of these two agents 
when compared with each single agent alone. Thus, the anticancer effect of the combination treatment of resveratrol and matrine was also evaluated in HepG2 cells.

\section{Materials and methods}

Cell culture and reagents. Matrine (purity $>98 \%$ ) was obtained from the National Institute for the Control of Pharmaceutical and Biological Products (Beijing, China). Resveratrol (purity $\geq 99 \%$ ), 3-(4,5-dimethyl-2-thiazoyl)-2,5-diphenyl-2H-tetrazolium bromide (MTT) and propidium iodide (PI) were purchased from Sigma-Aldrich (St. Louis, MO, USA). The Annexin V/PI double staining kit was purchased from Nanjing KeyGen Biotech., Co., Ltd. (Nanjing, China). The HepG2 cells were purchased from the American Type Culture Collection (Rockville, MD, USA). The cells were maintained in DMEM supplemented with $10 \%$ fetal bovine serum, $100 \mu \mathrm{g} / \mathrm{ml}$ streptomycin and $100 \mathrm{U} / \mathrm{ml}$ penicillin at $37^{\circ} \mathrm{C}$ in a humidified atmosphere with $5 \% \mathrm{CO}_{2}$.

Cell viability assay. MTT assay was used to assess cell viability. HepG2 cells were seeded into 96-well plates at a cell density of 5,000/well and allowed to adhere for $24 \mathrm{~h}$, followed by resveratrol and/or matrine treatment for $48 \mathrm{~h}$. Then $5 \mu \mathrm{l}$ of $5 \mathrm{mg} / \mathrm{ml}$ MTT was added to the medium and incubated for $2 \mathrm{~h}$ at $37^{\circ} \mathrm{C}$. After removing the culture medium, $100 \mu \mathrm{l}$ of DMSO was added. The plates were read using an enzyme-linked immunosorbent assay plate reader at $570 \mathrm{~nm}$. All experiments were performed in triplicate, and the cell viability of HepG2 cells was calculated as the ratio of each experimental condition to the control. The $\mathrm{IC}_{50}$ value was calculated from the nonlinear regression analysis.

Cell cycle analysis. To determine cell cycle distribution, HepG2 cells were treated with resveratrol for $24 \mathrm{~h}$. The cells were trypsinized and fixed with cold $70 \%$ ethanol overnight at $4^{\circ} \mathrm{C}$. Then the fixed cells were washed twice with phosphate-buffered saline (PBS) and incubated with $100 \mu \mathrm{g} / \mathrm{ml}$ of ribonuclease $\mathrm{A}$ at $37^{\circ} \mathrm{C}$ for $30 \mathrm{~min}$ and then stained with $50 \mu \mathrm{g} / \mathrm{ml}$ PI for $1 \mathrm{~h}$. The fluorescence intensity was detected using BD FACSCalibur cytometer, and the cell cycle distribution was assayed using ModFit LT software (both from BD Biosciences, San Jose, CA, USA).

Colony formation assay. HepG2 cells were seeded into 6-well plates at a density of 400 cells/well. After overnight incubation, the cells were exposed to resveratrol and/or matrine for $48 \mathrm{~h}$. Thereafter, the drugs were removed by replacing the medium with fresh medium, and the cells were then maintained in culture for another 10 days and the medium was replaced every three days, during which time the surviving cells produced colonies. The colonies were visualized by staining for $4 \mathrm{~h}$ with $1 \%$ methylene blue (in 100\% methanol), and the colonies that contained $>50$ cells were counted. The colony formation efficacy was calculated according to the following formula: Colony formation efficacy $=$ colony counts/seeded cells x $100 \%$. All experiments were performed in triplicate.

Synergy between the resveratrol and matrine combination. The nature of the combined effect of resveratrol and matrine was determined using the method described by George et al (9), based on the principles described by Chou and Talalay (18). In brief, the expected value of the combined effect between agent 1 and 2 is calculated as: [(observed agent 1 value)/(control value)] x [(observed agent 2 value)/(control value)] x (control value); and the ratio is calculated as (expected value)/(observed value). A ratio of $>1$ indicates a synergistic effect, and a ratio of $<1$ indicates a less than additive effect.

Quantification of apoptosis. HepG2 cells were seeded in 6-well plates at a density of $3 \times 10^{5}$ cells/well and exposed to resveratrol and/or matrine treatment for $48 \mathrm{~h}$. The cells were harvested and washed twice in PBS, and then resuspended in $500 \mu \mathrm{l}$ binding buffer at a density of $1 \times 10^{6}$ cells $/ \mathrm{ml}$. The cell suspension was incubated with $5 \mu 1$ Annexin V and $5 \mu \mathrm{l}$ PI in the dark for $15 \mathrm{~min}$ at room temperature. Finally, apoptotic cells were detected by flow cytometry. The amount of apoptosis was evaluated as the percentage of Annexin $\mathrm{V}^{+} / \mathrm{PI}^{-}$and Annexin $\mathrm{V}^{+} / \mathrm{PI}^{+}$cells.

Western blot analysis. Western blot analysis was performed as previously described (19). In brief, after treatment with resveratrol and/or matrine, HepG2 cells were collected, lysed and subjected to 7.5-12.5\% sodium dodecyl sulfatepolyacrylamide gel and transferred onto a polyvinylidene fluoride membrane. After blocking with 5\% non-fat milk in the blocking buffer (PBS containing 0.1\% Tween-20, pH 7.5), the membrane was probed with designated first and second antibodies. The immunoreactive bands were visualized using the ECL Plus Western Blotting Detection System (Piscataway, NJ, USA). The level of $\beta$-actin was used as a loading control. The antibody against caspase-3 and caspase-9, poly(ADPribose) polymerase-1 (PARP-1), p53, survivin, Bax, Bcl-2 were purchased from Cell Signaling Technology, Inc. (Danvers, MA, USA). The antibodies against $\beta$-actin were purchased from Sigma-Aldrich.

Reactive oxygen species (ROS) and mitochondrial membrane potential $\left(\Delta \psi_{m}\right)$ assays. HepG2 cells were seeded into 6-well plates at a density of $3 \times 10^{5}$ cells/well. After overnight incubation, the cells were treated with resveratrol and/or matrine for $24 \mathrm{~h}$. Then the HepG2 cells for the detection of ROS were incubated with $10 \mu \mathrm{M} \mathrm{H}_{2} \mathrm{DCFDA}$ at $37^{\circ} \mathrm{C}$ for $30 \mathrm{~min}$ in the dark. For the $\Delta \psi_{\mathrm{m}}$ assay, the HepG2 cells were incubated with $0.5 \mathrm{mM}$ Rhodamine 123 at $37^{\circ} \mathrm{C}$ for $30 \mathrm{~min}$ in the dark. The intracellular fluorescence intensity was measured with a $\mathrm{BD}$ FACSCalibur cytometer.

Statistical analysis. All experiments were repeated as least three times. One-way analysis of variance (ANOVA) was used to analyze the variance for the means of multiple groups. Statistical analysis was performed using SPSS, and significant differences were considered at values of $\mathrm{P}<0.05$.

\section{Results}

Resveratrol inhibits HepG2 cell proliferation. The effect of resveratrol on the cell proliferation of HepG2 cells was evaluated by the MTT assay. The viability of HepG2 cells was decreased significantly when resveratrol was used at 


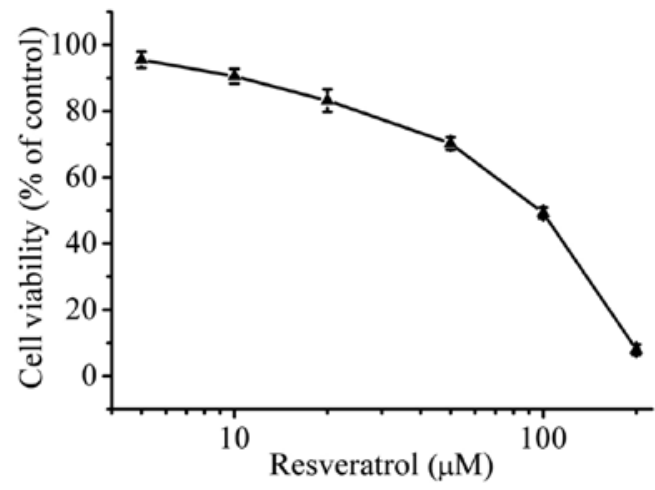

Figure 1. Effect of resveratrol on the cell proliferation of HepG2 cells. HepG2 cells were treated with increasing concentrations of resveratrol $(0,5,10,20$, $50,100,200 \mu \mathrm{M})$ for $48 \mathrm{~h}$, and the percentage of viable cells was then determined using the MTT assay. Error bars represent the means \pm SEM for three independent experiments.
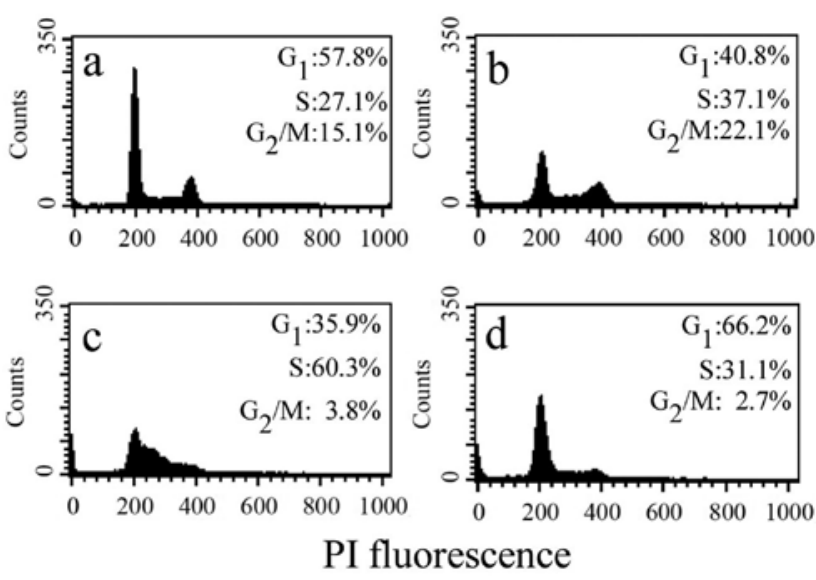

Figure 2. Effect of resveratrol on the cell cycle distribution of HepG2 cells. HepG2 cells were subjected to cell cycle analysis after treatment with (a) 0 , (b) 20 , (c) 50 and (d) $100 \mu \mathrm{M}$ resveratrol for $24 \mathrm{~h}$. A representative result of three independent experiments is shown.

concentrations $>10 \mu \mathrm{M}(\mathrm{P}<0.05)$ (Fig. 1). The cell viabilities at $10,20,50$ and $100 \mu \mathrm{M}$ concentrations of resveratrol were recorded as $91,83,70$ and $46 \%$, respectively. The results showed that resveratrol inhibited the growth of HepG2 cells in a dose-dependent manner. The $\mathrm{IC}_{50}$ value was $70 \mu \mathrm{M}$ after incubation for $48 \mathrm{~h}$.

Resveratrol arrests HepG2 cells in the $G_{1}$ and $S$ phase in HepG2 cells. To explore the growth-inhibitory mechanisms of resveratrol, the effect of resveratrol on cell cycle perturbations was examined. The cell cycle profile was assessed in HepG2 cells after exposure to $0,20,50$ and $100 \mu \mathrm{M}$ resveratrol for $24 \mathrm{~h}$. A clear dose-dependent cell cycle arrest was observed in the HepG2 cells (Fig. 2). At lower concentrations of resveratrol (20 and $50 \mu \mathrm{M})$, the number of HepG2 cells increased in the $\mathrm{S}$ phase. However, when resveratrol was used at a higher concentration $(100 \mu \mathrm{M})$, there was a considerable accumulation of cells in the $G_{1}$ phase. These results indicate that resveratrol arrests the cell cycle in the $G_{1}$ and $S$ phase in a concentration-dependent manner.
A

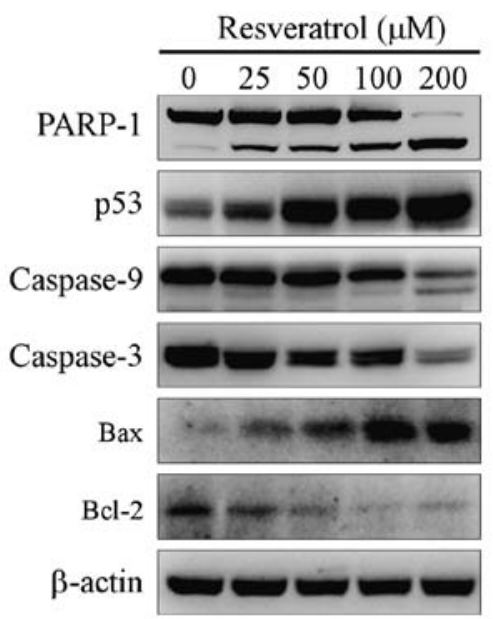

B

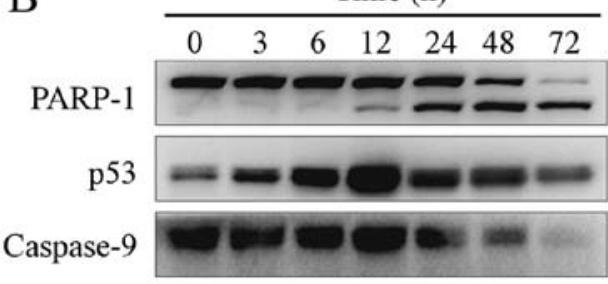

Caspase-3

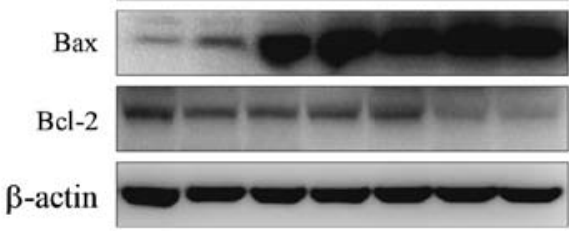

Figure 3. Effect of resveratrol on the apoptosis of HepG2 cells. HepG2 cells were treated with various concentrations of resveratrol $(0,25,50,100$ and $200 \mu \mathrm{M}$ ) for $48 \mathrm{~h}(\mathrm{~A})$ or $100 \mu \mathrm{M}$ resveratrol for the indicated times (B) and then western blotting was used to analyze the status of PARP-1, p53, Bax, Bcl-2, caspase-3 and -9. $\beta$-actin was used as a loading control. A representative result of three independent experiments is shown. PARP-1, poly(ADP-ribose) polymerase-1.

Resveratrol triggers apoptosis in HepG2 cells. In order to determine whether apoptosis participates in resveratrolinduced cell death, the expression levels of PARP-1, Bcl-2, Bax, p53, caspase-3 and -9 were measured by western blotting. Resveratrol increased PARP-1 cleavage and caspase-3 and caspase- 9 activation, which are hallmarks of an increase in apoptosis, in a dose- and time-dependent manner (Fig. 3). Resveratrol also inhibited anti-apoptotic protein Bcl-2 expression and upregulated expression of pro-apoptotic protein Bax and tumor suppressor protein $\mathrm{p} 53$. Therefore, resveratrol induced apoptotic cell death via a caspase- and p53-dependent pathway.

Resveratrol and matrine synergistically inhibit the growth of HepG2 cells. The effect of matrine on the growth of HepG2 cells was evaluated by the MTT assay. Matrine inhibited the growth of HepG2 cells in a dose-dependent manner (Fig. 4A). However, matrine treatment at concentrations $<2 \mathrm{mM}$ only resulted in a slight decrease in cell survival rate. To assess whether matrine can enhance the anticancer activity of 

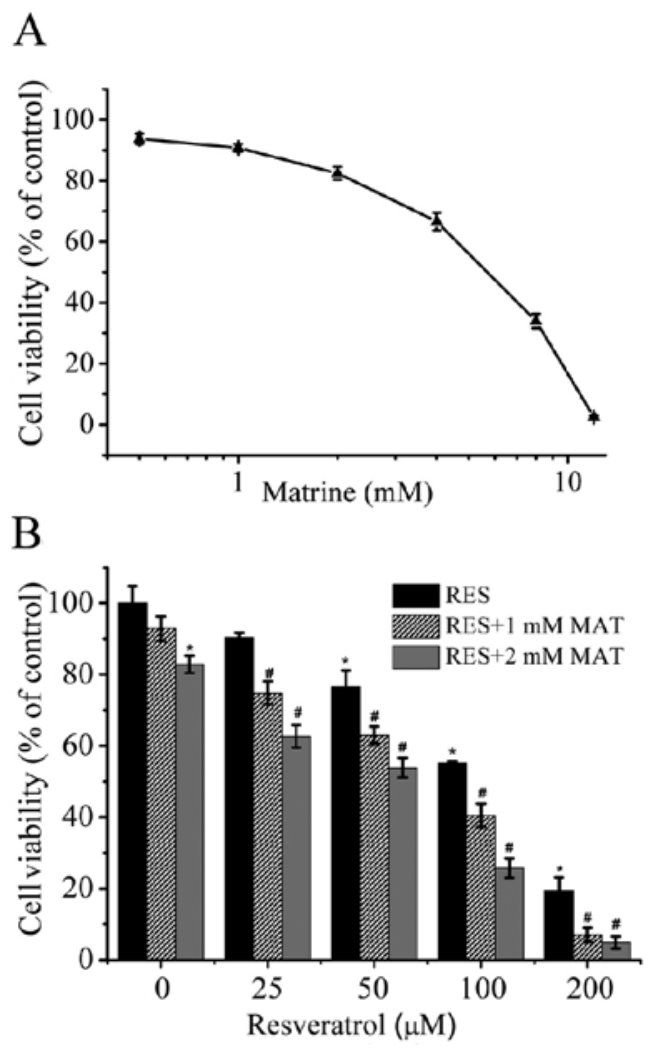

$\mathrm{C}$
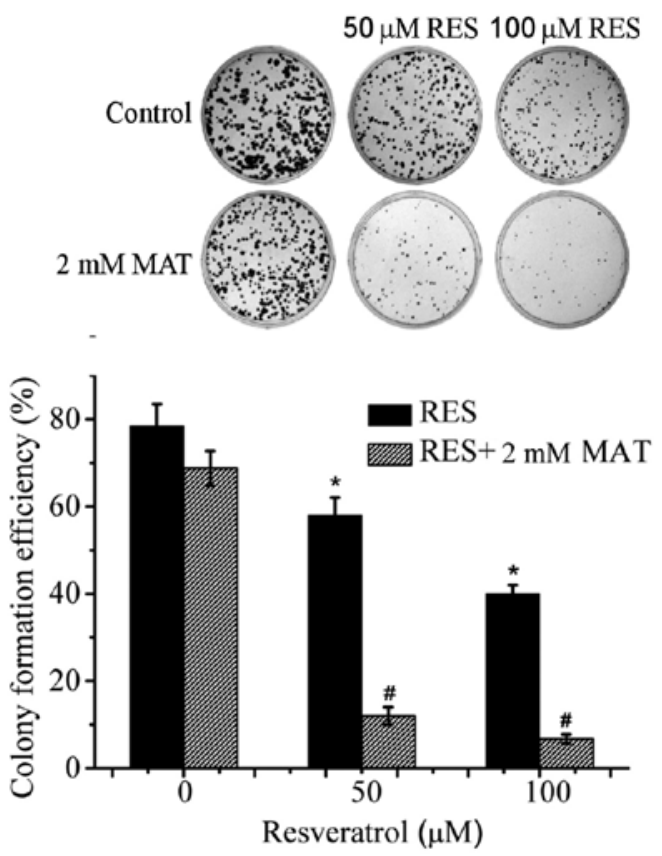

Figure 4. Combined effect of resveratrol and matrine on HepG2 cell proliferation. (A) HepG2 cells were treated with increasing concentrations of matrine $(0$, $0.5,1.0,2,4,8$ and $12 \mathrm{mM}$ ) for $48 \mathrm{~h}$, and the percentage of viable cells was then determined using the MTT assay. (B) HepG2 cells were treated with matrine $(1$ or $2 \mathrm{mM})$ and increasing concentrations of resveratrol $(0,25,50,100$ and $200 \mu \mathrm{M})$, alone or in combination, and then the percentage of viable cells was determined by the MTT assay. (C) Colony formation assay was used to confirm the growth-inhibitory effect of resveratrol $(0,50$ and $100 \mu \mathrm{M})$ with or without $2 \mathrm{mM}$ matrine. Error bars represent the means \pm SEM for three independent experiments. ${ }^{*} \mathrm{P}<0.05$ compared with the control, ${ }^{\#} \mathrm{P}<0.05$ compared with each agent alone. MAT, matrine. RES, resveratrol.

Table I. Synergistic antiproliferative effect between resveratrol and matrine combination on HepG2 cells.

\begin{tabular}{lccc}
\hline Treatment & $\begin{array}{c}\text { Observed } \\
\text { value }\end{array}$ & $\begin{array}{c}\text { Expected } \\
\text { value }\end{array}$ & Ratio $^{\mathrm{a}}$ \\
\hline $50 \mu \mathrm{M}$ resveratrol+matrine & 0.12 & 0.51 & 4.25 \\
$100 \mu \mathrm{M}$ resveratrol+matrine & 0.07 & 0.35 & 5.00 \\
\hline
\end{tabular}

${ }^{\text {aRatio }}=($ expected value/observed value $)$. A ratio of $>1$ indicates a synergistic effect and a ratio of $<1$ indicates a less than additive effect.

resveratrol, we treated HepG2 cells with increasing concentrations of resveratrol $(25,50,100$ and $200 \mu \mathrm{M})$ in the presence or absence of matrine (1 or $2 \mathrm{mM}$ ) for $48 \mathrm{~h}$. The MTT assay results showed that the combination treatment was more effective in inhibiting the proliferation of HepG2 cells when compared with either agent alone (Fig. 4B).

In order to confirm the growth-inhibitory effect of the combination treatment of resveratrol and matrine, a colony formation assay was also used to further study the combined treatment of resveratrol and matrine. HepG2 cells were treated with increasing concentrations of resveratrol (50 and $100 \mu \mathrm{M}$ ) with or without $2 \mathrm{mM}$ matrine. When resveratrol was combined with matrine, the colony formation efficacy of the
HepG2 cells was significantly reduced when compared with either agent alone $(\mathrm{P}<0.05)$ (Fig. $4 \mathrm{C})$. The precise nature of this combination was further analyzed by the method described by George et al (9). The expected effect of the combination treatment on the cell proliferation was greater than the observed combination, suggesting a synergistic effect between resveratrol and matrine on HepG2 cells (Table I). Based on these results, we selected $50 \mu \mathrm{M}$ resveratrol and $100 \mu \mathrm{M}$ resveratrol in the presence or absence of matrine $(2 \mathrm{mM})$ to carry out the subsequent studies.

Matrine enhances resveratrol-induced apoptosis in HepG2 cells. To understand the molecular basis of the growthinhibitory mechanism caused by resveratrol and matrine, Annexin V/PI double staining was used to quantify the extent of apoptosis after $48 \mathrm{~h}$ treatment with resveratrol and/or matrine. When matrine was combined with resveratrol, matrine significantly enhanced resveratrol-induced apoptosis of HepG2 cells $(\mathrm{P}<0.05)$ (Fig. 5A). We further detected the effects of resveratrol and/or matrine on apoptosis-related proteins. The combination treatment of resveratrol and matrine significantly enhanced the cleavage of PARP-1, activation of caspase-3 and caspase-9 when compared to either agent alone (Fig. 5B). In addition, the combined treatment significantly inhibited survivin expression in HepG2 cells compared to the expression following treatment with either agent alone. 

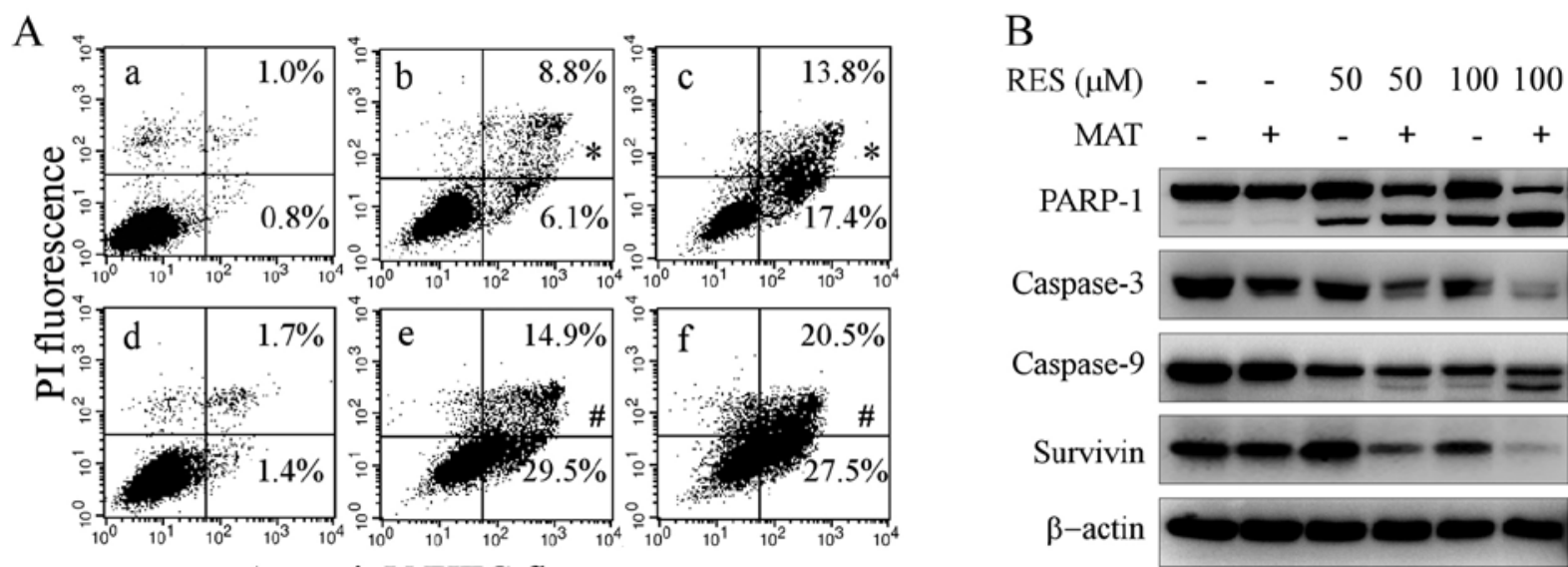

AnnexinV-FITC fluorescence

Figure 5. Enhancing resveratrol-induced apoptosis by matrine in HepG2 cells. HepG2 cells were treated with (a) 0 , (b) $50 \mu \mathrm{M} \mathrm{RES,} \mathrm{(c)} 100 \mu \mathrm{M}$ RES, (d) $2 \mathrm{mM}$ MAT, (e) 2 mM MAT+50 $\mu \mathrm{M}$ RES, (f) 2 mM MAT+100 $\mu \mathrm{M}$ RES for $48 \mathrm{~h}$. (A) Annexin V/PI double staining was used to quantify apoptosis. The amount of apoptosis was evaluated as the percentage of Annexin $\mathrm{V}^{+} / \mathrm{PI}^{-}$and Annexin $\mathrm{V}^{+} / \mathrm{PI}^{+}$cells. (B) Western blotting was used to analyze the status of PARP-1, caspase-3, -9 and survivin. $\beta$-actin was used as a loading control. ${ }^{*} \mathrm{P}<0.05$ compared with the control, ${ }^{\prime} \mathrm{P}<0.05$ compared with each agent alone. RES, resveratrol; MAT, matrine; PARP-1, poly(ADP-ribose) polymerase-1.

A
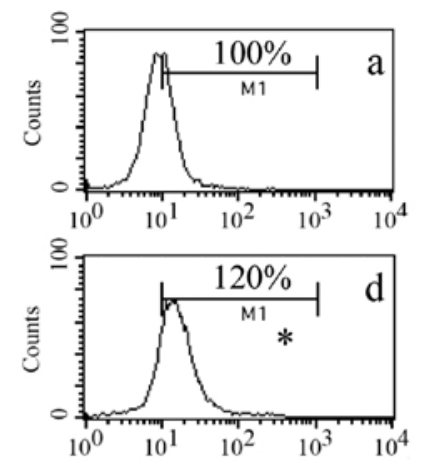

B
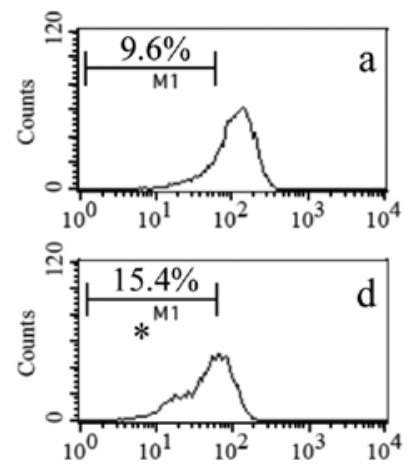
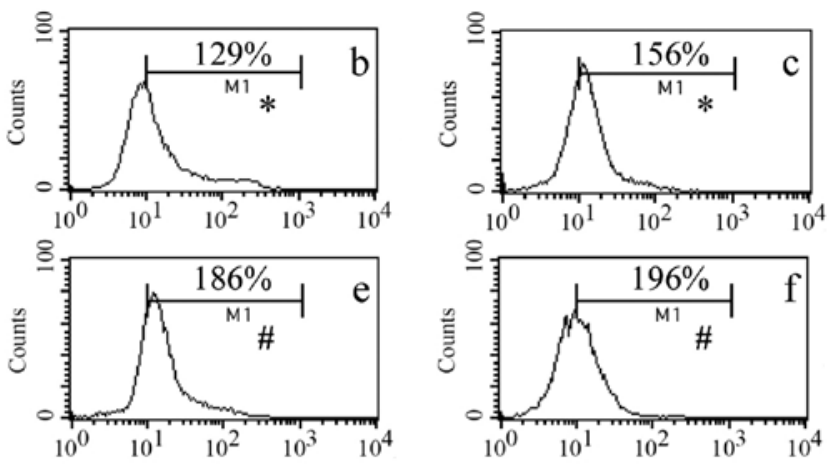

$\mathrm{H}_{2}$ DCFDA fluorescence
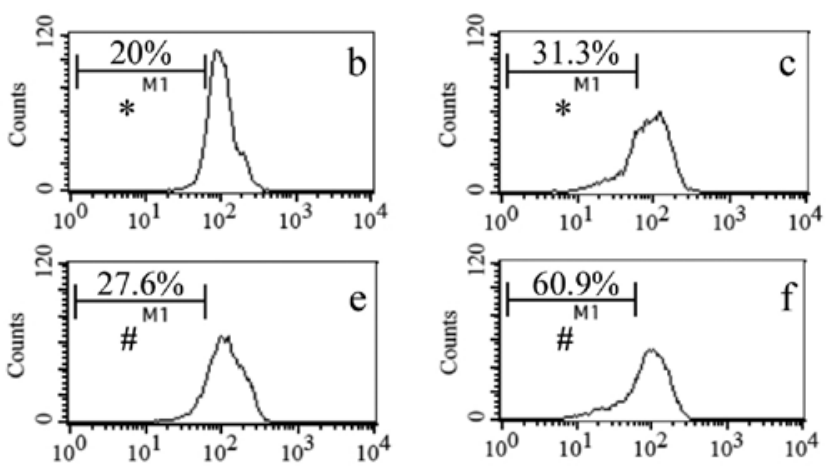

Rho123 fluorescence

Figure 6. Induction of ROS generation and disruption of $\Delta \psi_{\mathrm{m}}$ by the combined treatment of resveratrol and matrine in HepG2 cells. HepG2 cells were treated with (a) 0 , (b) $50 \mu \mathrm{M}$ RES, (c) $100 \mu \mathrm{M}$ RES, (d) $2 \mathrm{mM}$ MAT, (e) $2 \mathrm{mM}$ MAT+50 $\mu \mathrm{M}$ RES, (f) $2 \mathrm{mM}$ MAT+100 $\mu \mathrm{M}$ RES for $48 \mathrm{~h}$. (A) After treatment, the cells were stained with $\mathrm{H}_{2}$ DCFDA for 30 min and then analyzed by flow cytometry. (B) After staining with Rhodamine 123 for 30 min, the cells were assayed with a FACSCalibur. " $\mathrm{P}<0.05$ compared with the control, ${ }^{\prime} \mathrm{P}<0.05$ compared with each agent alone. ROS, reactive oxygen species; MAT, matrine. RES, resveratrol.

Combined treatment of resveratrol and matrine induces ROS generation and decreases $\triangle \psi_{m}$ in HepG2 cells. In order to study the mechanisms of the apoptosis induced by the combined treatment, we further examined the combined effect of resveratrol and matrine on ROS production in HepG2 cells after $24 \mathrm{~h}$ treatment. The combined treatment significantly induced ROS generation in the HepG2 cells when compared with either agent alone $(\mathrm{P}<0.05)($ Fig. 6A). To better characterize the apoptotic cell death induced by resveratrol and matrine in HepG2, the role of mitochondria was also evalu- 
ated after the treatment of resveratrol and/or matrine for $24 \mathrm{~h}$. The combined treatment of resveratrol and matrine caused a marked loss of $\Delta \psi_{\mathrm{m}}$ in the HepG2 cells in respect to each agent alone $(\mathrm{P}<0.05)$ (Fig. 6B).

\section{Discussion}

Previous studies have demonstrated that resveratrol inhibits the proliferation of various types of tumor cells in vivo and in vitro (20-22). In the present study, we showed that resveratrol decreased the viability of HepG2 cells in a dose-dependent manner. In addition, we further dissected the mechanisms underlying the antitumor effect of resveratrol. Resveratrol arrested HepG 2 cells in the $G_{1}$ and $S$ phase which is consistent with reported findings (23), suggesting that retardation of cell cycle progression may be one of the mechanisms underlying the antitumor effect of resveratrol.

Apoptosis, or programed cell death, is a well-documented phenomenon in many cellular systems, which has been recognized as a major anticancer therapeutic response (24). Our findings are consistent with previous reports that resveratrol induces apoptosis in cancer cells (25-27). In the present study, we confirmed that resveratrol induced apoptosis in HepG 2 cells, as shown by the cleavage of PARP-1, the upregulation of p53 expression and the activation of caspase-9 and caspase-3. Caspase-9 is an initiator in the mitochondrial death pathway (the intrinsic pathway), which could be activated by apoptosomes formed by cytochrome $c$, Apaf-1 and pro-caspase-9 (28). Then activated caspase-9 can cleave and activate caspase-3. Caspase-3, as an effector caspase, initiates the hallmark of the degradation process of apoptosis, such as cell shrinkage, membrane blebbing, DNA fragmentation and finally the breakdown of the cell into smaller units (apoptotic bodies) (29). The Bcl-2 family members Bax and Bcl-2 serve as critical regulators of the mitochondrial-dependent apoptotic pathway. Bcl-2 that negatively regulates apoptosis promotes cell survival, whereas Bax that positively regulates apoptosis stimulates mitochondrial damage (30). Consistent with the ability of resveratrol to kill HepG2 cells via apoptotic processes, resveratrol upregulated the ratio of $\mathrm{Bax} / \mathrm{Bcl}-2$, indicating that the increased ratio of $\mathrm{Bax} / \mathrm{Bcl}-2$ may trigger resveratrol-induced apoptosis in HepG2 cells.

Matrine has been approved as an adjuvant drug for the treatment of various malignant cancers in China (11). However, matrine alone weakly inhibits proliferation of cancer cell lines with an $\mathrm{IC}_{50}$ value of 2-16 $\mathrm{mM}$ (17). Combination of anticancer agents for cancer therapy and prevention has been extensively studied in numerous in vivo and in vitro models $(31,32)$. Since each agent may have its own targets and also share common targets, the combination of two anticancer agents may exert a synergistic effect. Thus, the effect of the combined treatment of resveratrol and matrine on HepG2 cells was also evaluated here. The combined treatment significantly enhanced the antiproliferative effect when compared with either agent alone. The ratio of expected value/observed value was $>1$ for the concentrations tested, indicating that the combined treatment of resveratrol and matrine exhibited a synergistic antiproliferative effect. To our knowledge, the present study was the first to investigate the effect of the combination treatment of resveratrol and matrine on cancer cells. The combination treatment significantly induced apoptotic cell death in HepG2 cells as compared to either agent alone, indicating that induction of apoptosis is an important mechanism of enhancing the anticancer effects of resveratrol by matrine.

Survivin is a member of the inhibitors of apoptosis-related proteins, which has been found to be frequently overexpressed in most types of cancer cells, including HCC cells. Therefore, survivin has emerged as a potential therapeutic target for natural anticancer compounds $(33,34)$. Our results showed that the combination treatment of resveratrol and matrine significantly reduced the expression of survivin in HepG2 cells compared with the control or either drug alone. These data suggest that downregulation of survivin expression is also involved in the antiproliferative effects of the combined treatment.

ROS are known to disrupt $\Delta \psi_{\mathrm{m}}$, and therefore trigger a series of mitochondrial-associated events (35). A high level of ROS leads to oxidative stress, loss of cell function and ultimately apoptosis or necrosis (36). Natural products may exert anticancer effects by inducing ROS-mediated apoptosis. Both resveratrol and matrine were found to induce ROS production in cancer cell lines (37-39). However, there is no evidence of the combined effect of resveratrol and matrine on ROS generation. In the present study, we demonstrated that the combination treatment significantly enhanced the generation of ROS in HepG2 cells when compared with either agent alone. Furthermore, the combined treatment also resulted in loss of $\Delta \psi_{\mathrm{m}}$. Therefore, induction of ROS generation and disruption of $\Delta \psi_{\mathrm{m}}$ are involved in potentiating resveratrol-induced apoptosis by matrine.

Taken together, resveratrol exhibits multiple anticancer effects by inducing cell growth inhibition, cell cycle arrest and apoptosis in HepG2 cells. Moreover, the present study is the first to demonstrate that the combination treatment of resveratrol and matrine exhibits a synergistic antiproliferative effect on HepG2 cells. Therefore, the combined treatment of resveratrol and matrine is an effective and promising strategy for the prevention and treatment of liver cancer.

\section{Acknowledgements}

This study was supported by the Central Research Institutes of Basic Research and Public Service Special Operations in 2013.

\section{References}

1. Jemal A, Bray F, Center MM, Ferlay J, Ward E and Forman D: Global cancer statistics. CA Cancer J Clin 61: 69-90, 2001.

2. Yang JD and Roberts LR: Hepatocellular carcinoma: a global view. Nat Rev Gastroenterol Hepatol 7: 448-458, 2010.

3. El-Serag HB: Hepatocellular carcinoma. N Engl J Med 365: 1118-1127, 2011.

4. Llovet JM, Ricci S, Mazzaferro V, et al: Sorafenib in advanced hepatocellular carcinoma. N Engl J Med 359: 378-390, 2008.

5. Je Y, Schutz FA and Choueiri TK: Risk of bleeding with vascular endothelial growth factor receptor tyrosine-kinase inhibitors sunitinib and sorafenib: a systematic review and meta-analysis of clinical trials. Lancet Oncol 10: 967-974, 2009.

6. Jang M, Cai L, Udeani GO, et al: Cancer chemopreventive activity of resveratrol, a natural product derived from grapes. Science 275: 218-220, 1997.

7. Bishayee A, Politis T and Darvesh AS: Resveratrol in the chemoprevention and treatment of hepatocellular carcinoma. Cancer Treat Rev 36: 43-53, 2010. 
8. Wu SL, Sun ZJ, Yu L, Meng KW, Qin XL and Pan CE: Effect of resveratrol and in combination with 5-FU on murine liver cancer. World J Gastroenterol 10: 3048-3052, 2004.

9. George J, Singh M, Srivastava AK, et al: Resveratrol and black tea polyphenol combination synergistically suppress mouse skin tumors growth by inhibition of activated MAPKs and p53. PLoS One 6: e23395, 2011.

10. Iwuchukwu OF, Tallarida RJ and Nagar S: Resveratrol in combination with other dietary polyphenols concomitantly enhances antiproliferation and UGT1A1 induction in Caco-2 cells. Life Sci 88: 1047-1054, 2011.

11. Wang Z, Zhang J, Wang Y, et al: Matrine, a novel autophagy inhibitor, blocks trafficking and the proteolytic activation of lysosomal proteases. Carcinogenesis 34: 128-138, 2013.

12. Zhang S, Zhang Y, Zhuang Y, et al: Matrine induces apoptosis in human acute myeloid leukemia cells via the mitochondrial pathway and Akt inactivation. PLoS One 7: e46853, 2012.

13. Zhou H, Xu M, Gao Y, et al: Matrine induces caspase-independent program cell death in hepatocellular carcinoma through bid-mediated nuclear translocation of apoptosis inducing factor. Mol Cancer 13: 59, 2014.

14. Zhang L, Wang T, Wen X, et al: Effect of matrine on HeLa cell adhesion and migration. Eur J Pharmacol 563: 69-76, 2007.

15. Jiang T, Zhu Y, Luo C, et al: Matrine inhibits the activity of translation factor eIF4E through dephosphorylation of 4E-BP1 in gastric MKN45 cells. Planta Med 73: 1176-1181, 2007.

16. Sun M, Cao H, Sun L, et al: Antitumor activities of kushen: literature review. Evid Based Complement Alternat Med 2012: 373219, 2012.

17. Yu Q, Chen B, Zhang X, Qian W, Ye B and Zhou Y: Arsenic trioxide-enhanced, matrine-induced apoptosis in multiple myeloma cell lines. Planta Med 79: 775-781, 2013.

18. Chou TC and Talalay P: Quantitative analysis of dose-effect relationships: the combined effects of multiple drugs or enzyme inhibitors. Adv Enzyme Regul 22: 27-55, 1984.

19. Gao N, Shang B, Zhang X, et al: Potent antitumor actions of the new antibiotic boningmycin through induction of apoptosis and cellular senescence. Anticancer Drug 22: 166-175, 2011

20. Joe AK, Liu H, Suzui M, Vural ME, Xiao D and Weinstein IB: Resveratrol induces growth inhibition, S-phase arrest, apoptosis, and changes in biomarker expression in several human cancer cell lines. Clin Cancer Res 8: 893-903, 2002.

21. Garvin S, Ollinger K and Dabrosin C: Resveratrol induces apoptosis and inhibits angiogenesis in human breast cancer xenografts in vivo. Cancer Lett 231: 113-122, 2006.

22. Baur JA and Sinclair DA: Therapeutic potential of resveratrol: the in vivo evidence. Nat Rev Drug Discov 5: 493-506, 2006.

23. Stervbo U, Vang O and Bonnesen C: Time- and concentrationdependent effects of resveratrol in HL-60 and HepG2 cells. Cell Prolif 39: 479-493, 2006.

24. Wong RS: Apoptosis in cancer: from pathogenesis to treatment. J Exp Clin Cancer Res 30: 87, 2011.
25. Jiang H, Zhang L, Kuo J, et al: Resveratrol-induced apoptotic death in human U251 glioma cells. Mol Cancer Ther 4: 554-561, 2005.

26. Kai L, Samuel SK and Levenson AS: Resveratrol enhances p53 acetylation and apoptosis in prostate cancer by inhibiting MTA1/ NuRD complex. Int J Cancer 126: 1538-1548, 2010.

27. Scarlatti F, Sala G, Somenzi G, Signorelli P, Sacchi N and Ghidoni R: Resveratrol induces growth inhibition and apoptosis in metastatic breast cancer cells via de novo ceramide signaling. FASEB J 17: 2339-2341, 2003.

28. Cepero E, King AM, Coffey LM, Perez RG and Boise LH: Caspase-9 and effector caspases have sequential and distinct effects on mitochondria. Oncogene 24: 6354-6366, 2005.

29. Kumar S: Caspase function in programmed cell death. Cell Death Differ 14: 32-43, 2007.

30. Bagci EZ, Vodovotz Y, Billiar TR, Ermentrout GB and Bahar I Bistability in apoptosis: roles of bax, bcl-2, and mitochondrial permeability transition pores. Biophys J 90: 1546-1559, 2006.

31. Du Q, Hu B, An HM, et al: Synergistic anticancer effects of curcumin and resveratrol in Hepa1-6 hepatocellular carcinoma cells. Oncol Rep 29: 1851-1858, 2013.

32. Pan X, Zhang X, Sun H, Zhang J, Yan M and Zhang H: Autophagy inhibition promotes 5-fluorouraci-induced apoptosis by stimulating ROS formation in human non-small cell lung cancer A549 cells. PLoS One 8: e56679, 2013

33. Singh RP, Dhanalakshmi S, Agarwal C and Agarwal R: Silibinin strongly inhibits growth and survival of human endothelial cells via cell cycle arrest and downregulation of survivin, Akt and $\mathrm{NF}-\kappa \mathrm{B}$ : implications for angioprevention and antiangiogenic therapy. Oncogene 24: 1188-1202, 2005.

34. Wang T, Wei J, Qian X, Ding Y, Yu L and Liu B: Gambogic acid, a potent inhibitor of survivin, reverses docetaxel resistance in gastric cancer cells. Cancer Lett 262: 214-222, 2008.

35. Circu ML and Aw TY: Reactive oxygen species, cellular redox systems, and apoptosis. Free Radic Biol Med 48: 749-762, 2010.

36. Kirkland RA and Franklin JL: Bax, reactive oxygen, and cytochrome $c$ release in neuronal apoptosis. Antioxid Redox Signal 5: 589-596, 2003.

37. Miki H, Uehara N, Kimura A, et al: Resveratrol induces apoptosis via ROS-triggered autophagy in human colon cancer cells. Int J Oncol 40: 1020-1028, 2012

38. Tan C, Qian X, Jia R, Wu M and Liang Z: Matrine induction of reactive oxygen species activates p38 leading to caspasedependent cell apoptosis in non-small cell lung cancer cells. Oncol Rep 30: 2529-2535, 2013.

39. Hussain AR, Uddin S, Bu R, et al: Resveratrol suppresses constitutive activation of AKT via generation of ROS and induces apoptosis in diffuse large B cell lymphoma cell lines. PLoS One 6: e24703, 2011. 